\title{
Capnocytophaga canimorsus Meningitis - Diagnosis with 16S rDNA PCR when Conventional Methods Failed to Identify the Causative Agent
}

Anurup Kumar

East Sussex Healthcare NHS Trust, East Bourne, United Kingdom

Corresponding Author: Anurup Kumar, East Sussex Healthcare NHS Trust, East Bourne, United Kingdom. Received date: February 04 2021; Accepted date: April 27, 2021; Published date: April 30, 2021

Citation: Anurup Kumar. (2021) Capnocytophaga canimorsus Meningitis-Diagnosis with 16S rDNA PCR when Conventional Methods Failed to Identify the Causative Agent. J. Clinical Research and Clinical Trials. 3(1); DOI: 10.31579/2693-4779/025

Copyright: Copyright (C) 2021, Anurup Kumar. This is an open access article distributed under the Creative Commons Attribution License, which permits unrestricted use, distribution, and reproduction in any medium, provided the original work is properly cited.

\begin{abstract}
Meningitis whether bacterial or viral, poses many challenges to clinicians as the causative agent is often not found. According to guidelines, it is standard to start empiric treatment before a Cerebrospinal Fluid (CSF) sample is obtained. Meningitis, if not diagnosed and treated early, can lead to high morbidity and mortality rates with serious neurological sequelae. While the most common cases of bacterial meningitis are related to Streptococcus pneumoniae and Neisseria meningitidis, this clinical case report found a rare case of meningitis caused by a zoonotic pathogen, Capnocytophaga canimorsus; a commensal found as part of the normal flora of dogs and cats. This rare organism was identified with the help of broad range $16 \mathrm{~S}$ ribosomal DNA Polymerase Chain Reaction (rDNA PCR), an emerging technique that is now increasingly useful in rapid diagnosis especially if the offending agent is not timely identified and conventional methods have failed, making diagnosis and management difficult for physicians.
\end{abstract}

Keywords: Capnocytophaga canimorsus Meningitis; 16S rDNA PCR; Causative Agent

\section{Background}

\section{Epidemiology}

Capnocytophaga canimorsus is a rare species that causes severe and often fatal infections in humans. The incidence in general population is very low. In a national survey carried out in the Netherlands, an incidence ratio of 0.67 cases per million per year was present [4]. As part of the normal flora, it is commonly present in the oral cavities of 67 to $86 \%$ of dogs and $55-84 \%$ of cats $[5,6]$.

\section{Microbiology}

Capnocytophaga canimorsus, (C. Canimorsus), historically known as 'dysgonic fermenter 2 (DF-2)' due to its slow-growing, fastidious and fermenting properties was first observed in 1976 by RA Bobo and EJ Newton (1976).). It was isolated from a patient who was bitten by a dog and consequently developed sepsis and meningitis [7, 8]. It is a gram negative, capnophilic (carbon-loving), catalase- and oxidase+ anaerobic bacillus and is one of 9 isolated species, including C. ochracea, C. gingivalis, C. cynodegmi, C. hemolytica, some of which are found inhabiting the human oral cavity [9]. 3 serovars (variants) of $\mathrm{C}$. Canimorsus (A, B and C) are known to cause nearly $90 \%$ of disease in humans [10].

Pathogenesis/clinical presentation/ diagnostic methods:
Capnocytophaga canimorsusus tillses sugars from glycoproteins in host cells. It prevents macrophages from killing bacteria by blocking release of Tumour Necrosis Factor alpha and various Interleukins including Iinterleukin-1, 6 and 8. It also has a unique lipo-polysaccharide capsule that inhibits complement-mediated fixation and eventual phagocytosis by macrophages - all contributing to its capacity of evasion from the human immune system

Canimorsus infection can present as sepsis, endocarditis, cellulitis, gangrene of digits, purpurafulminans, acute abdomen and rarely meningitis, all following a dog bite. However, contact in the form of licking or superficial scratches have also been reported to transmit the organism

Infection with this bacterium is typically seen in asplenic or immunecompromised patient.As the bacterium is incredibly fastidious and cultures slowly, it is often difficult to identify with conventional methods of culture and gram staining, thus making the diagnosis problematic.

Conventional techniques used in the identification include slow culture on blood-agar [18]. However, now a newer technique, 16S rDNA PCR or broad range gene sequencing is becoming increasingly vital. Especially in cases where the clinical suspicion for meningitis remains high and the causative organism remains elusive.

\section{Antibiotic Susceptibility}


C. Canimorsus is mostly susceptible to Penicillin, Cephalosporins and Carbapenems. Some resistant strains of Capnocytophaga that produce class D beta-lactamase respond well to Clindamycin [19].

This clinical case report a case of meningitis caused by C. canimorsus in a woman with no known risk factors, in whom 16S rRNA gene sequencing aided identification of the pathogen, when conventional methods like culture and quantitative PCR failed.

\section{Case Presentation}

A 70-year-old female with no prior history of immune suppression presented to the Emergency department with a three week history of tinnitus, 'fullness' in the ears and one day history of severe headache, hoarseness of voice, hearing loss and worsening ataxia. At the time of admission, the patient was found to be photophobic and had severe hearing impairment. Clinically, no other neurological abnormalities could be elicited. The patient had a previous history of breast cancer and head injury following a traumatic accident. She also had chronic issues with her balance and gait. This was attributed to the superficial siderosis found on imaging, possibly following the accidents that she had suffered earlier in her life.

\section{Investigations and Management}

Considering the presentation, the patient was immediately isolated and empirically treated with Intravenous Acyclovir and Ceftriaxone in line with the protocol for treatment of cases of suspected meningitis of unknown aetiology.

An urgent CT Scan of Head did not show any acute pathology, although it did revealed significant atrophy of Cerebellar Vermis which explained the chronic issues with gait. A Lumbar puncture was then undertaken, and the Cerebro-spinal fluid (CSF) analysis revealed the following: Glucose 1.4 (serum: 6.7); WCC: 96 (polymorphs $20 \%$ and lymphocytes: $80 \%$ ); Protein: 2.75; Lactate: 7.3; LDH: 191 (Table 1) - theseresults were not very typical of bacterial meningitis as it did not show predominant polymorph pleocytosis.

Both blood and CSF Cultures failed to grow any organism, hence treatment was continued with broad spectrum cover of Intravenous Ceftriaxone. Intravenous Acyclovir was however stopped as per Consultant Microbiologist advice. Quantitative Polymerase Chain Reaction (qPCR) which tests for specific and most common agents like meningo-coccal and pneumo-coccal organisms also came back negative.

We requested an MRI Head to further guide treatment. It revealed appearances in-keeping with the diagnosis of meningitis. An abnormal signal was noted within the occipital right lateral ventricle, the extra-axial spaces of the frontal convexities and to a lesser degree in the interhemispheric fissure. This was most likely thought to be secondary to infected CSF or pus (Figure 1). The scan also revealed superficial siderosis with cerebellar atrophy (possibly secondary to previous head injuries) further explaining the pre-existing ataxic gait.

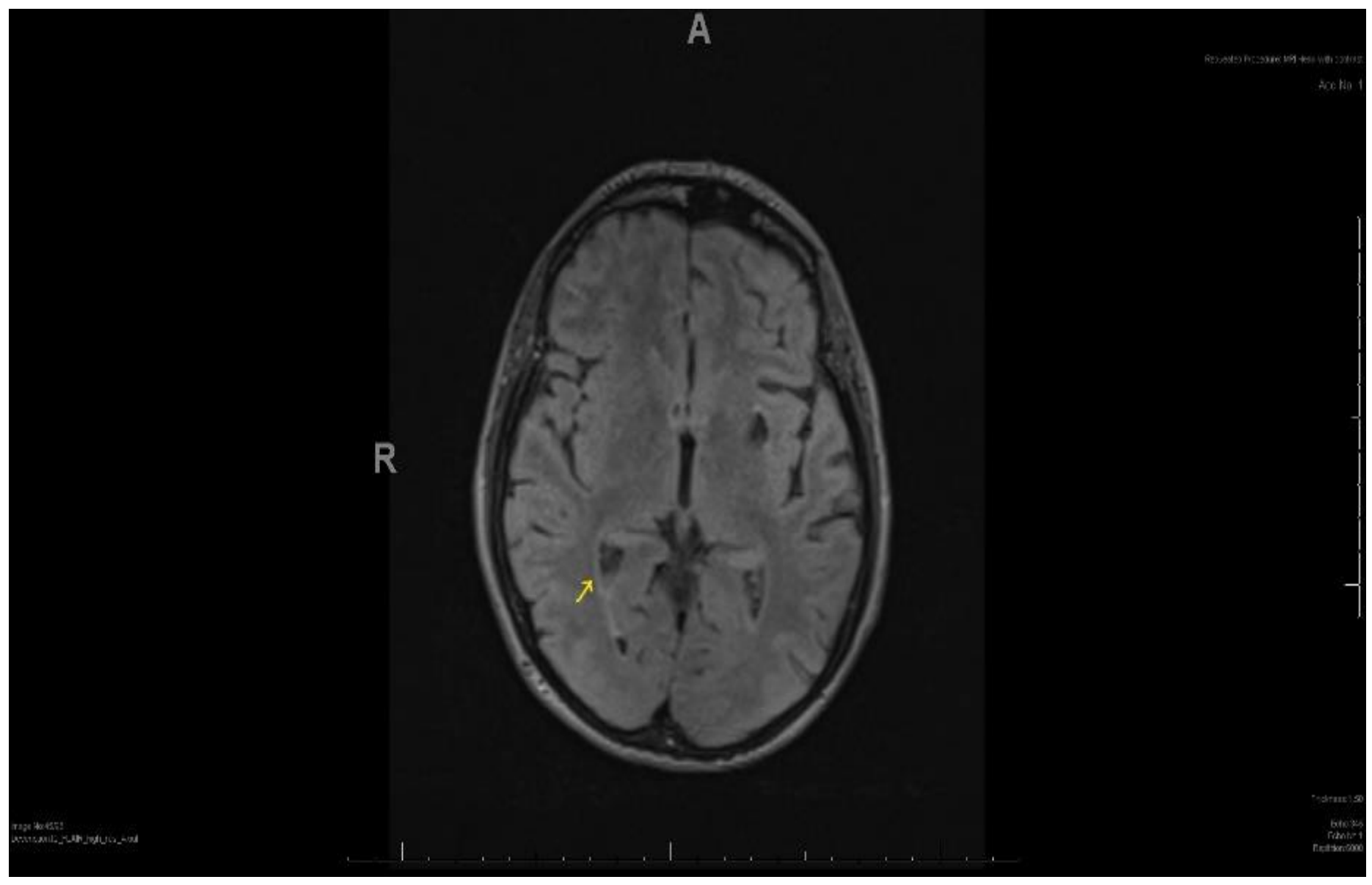




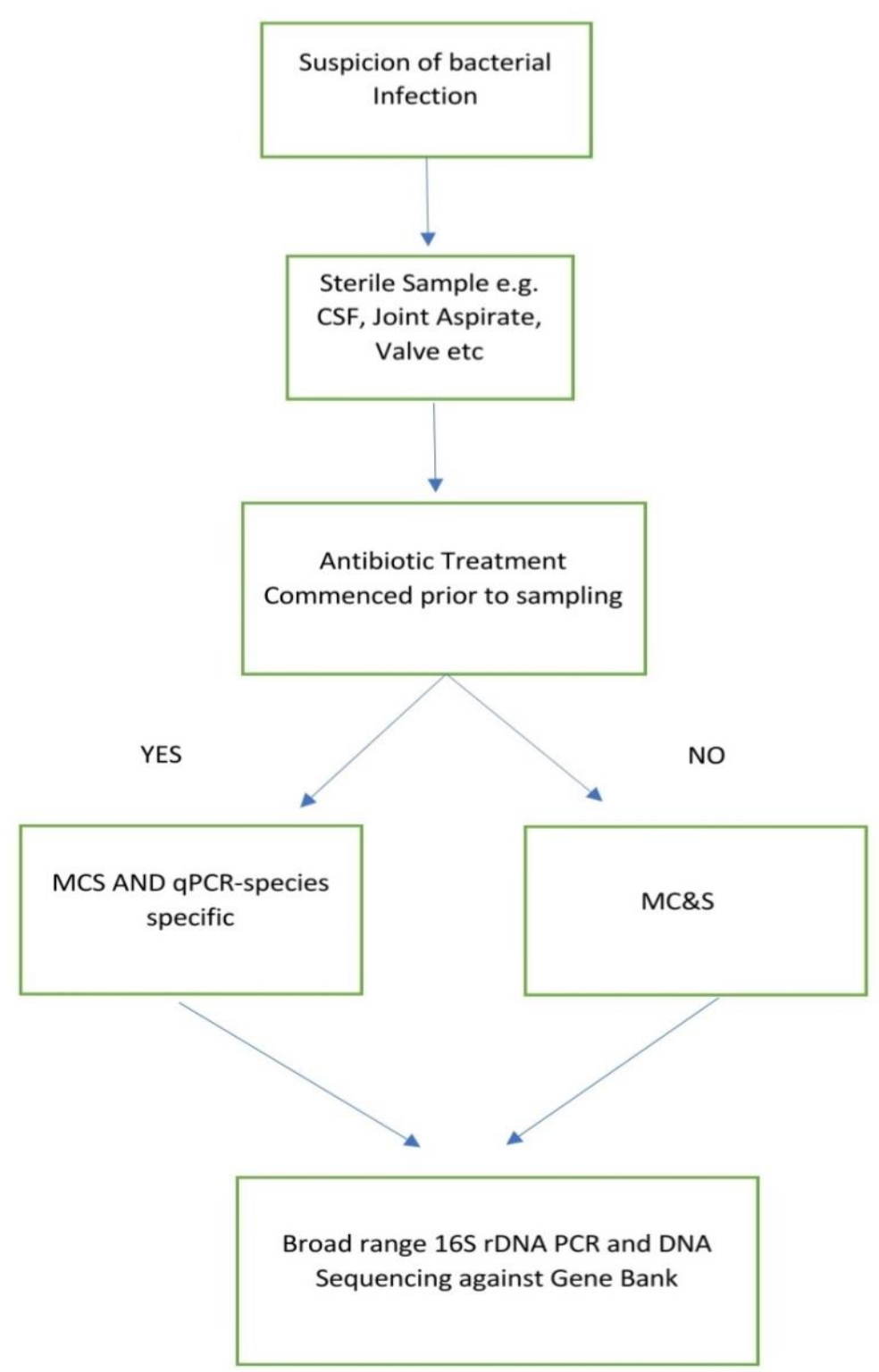

KEY: CSF - Cerebrospinal Fluid; MC\&S - Microscopy, Culture and Sensitivities

qPCR- quantitative Polymerase Chain Reaction

After approximately 10 days of initiation of treatment, a second CSF sample was sent for analysis, to assess for response. The symptoms had failed to improve during this time. The results revealed signs of active infection with high proteins: 2.64, WCC: 106 and Lact: 4.2 (Table 1). In consistency with the ongoing symptoms of the patient and considering the treatment was continued for further 2 weeks during which the patient reported improvement in symptoms. The causative agent, however was still elusive at this stage. Therefore, to check for response to treatment, a third CSF analysis was undertaken, the results of which were reassuring. By this time Microbiologist alerted us that the causative agent had finally been identified to be Capnocytophaga canimorsus via broad range $16 \mathrm{~S}$ rDNA PCR technique. 


\begin{tabular}{|c|c|c|c|c|c|}
\hline $\begin{array}{c}\text { Lumbar } \\
\text { Puncture/Csf } \\
\text { Analysis }\end{array}$ & WCC & Proteins & Glucose & Lactate & LDH \\
\hline $1^{\text {st }}$ & $\begin{array}{c}98(80 \% \\
\text { lymphocytes; } \\
20 \% \text { PMNs })\end{array}$ & 2.75 & 1.2 & 7.3 & 191 \\
\hline $2^{\text {nd }}$ & 106 & 2.64 & 1.4 & 4.2 & 90 \\
\hline $3^{\text {rd }}$ & 41 & 0.95 & 2.2 & 2.7 & 46 \\
\hline
\end{tabular}

Table 1. WCC, Proteins, Glucose, Lactate and LDH

KEY: WCC- White Cell Count; LDH: Lactate Dehydrogenase; PMNs - Polymorph Neutrophils

Since the results from the $3^{\text {rd }}$ CSF sample had still shown evidence of active infection, we were advised to continue treatment with Meropenem. We observed dramatic clinical improvement and the patient also stated feeling steadier on her feet and started mobilising. The third CSF sample sent earlier tested negative by the 16SrDNA PCR for C. canimorsus. Also,during this time the patient had completed the required course of IV Meropenem and it was at this point the antibiotic therapy was withdrawn. The patient was kept under observation for a few more days to ensure full recovery.

The patient remained well afterwards and was seen by ENT to investigate the cause for the severe hearing impairment. Audiology tests revealed severe and profound Sensory-neural Hearing Loss (SNHL) in her right and left ear, respectively, presumably secondary to the bacterial meningitis considering the acuteness of nature and timeline of events. She was discharged and a follow-up was arranged in clinic.

\section{Differential Diagnosis}

The main relevant differential diagnosis that were being considered till the agent was identified were of viral/ tuberculous meningitis, leading to the initiation of empirical treatment with an antiviral (Acyclovir) and broad-spectrum antibiotics - (Ceftriaxone). There was also an initial view that the patient might have had a Sub-arachnoid Haemorrhage which was then ruled out by imaging.

\section{Outcome and Follow-Up}

The patient was discharged following successful treatment and has been referred for a follow-up in ENT for her hearing impairment and Neurology clinic for her on-going chronic issues with balance. This was believed to be a consequence of her previous brain bleeds and cerebellar atrophy which had worsened due to the acute infection. She preferred to go to a private facility for a period of rehabilitation following her discharge and has remained well.

\section{Discussion}

In 1977, Butler et al. (1977) reported a series of cases with a similar, not yet identified gram negative bacillus, later identified as the same species by the Centre of Disease Control. Since then many cases have been published in literature; however, considering that this bacterial species is only now being recognised mainly due to the advances in molecular techniques. Especially, considering the close relation between man and dog ever since domestication, it may be more common and have an incidence rate much higher than earlier thought [21, 22].

According to available evidence, this organism is most commonly found in the immune-compromised. However, a recent systematic case review undertaken by Hansen and Crum-Cianflone (1977) has disputed this evidence. It showed that out of all cases of C. canimorsus meningitis recorded between 1966 and 2018, only a small minority were found to be immuno-compromised [23]. Out of a total of 37 patients, only $16 \%$ had a history of splenectomy and only $5 \%$ reported steroid use. Blood cultures were found to be positive only in $54 \%$ patients. $70 \%$ had positive CSF cultures. PCR was able to identify the organism in $22 \%$ of the cases. Antibiotic therapy ranged from 7 to 42 days. Disease prognosis was found to be better for meningitis, with only 1 reported fatality out of the total 37 cases reviewed in the article. 19\% of the patients suffered from neurological or physiological sequelae including hearing impairment and ataxia. Over $80 \%$ had a history of dog bite or had some form of non-bite exposure such as scratching or licking [24].

Hearing impairment, mostly sensorineural, like what we encountered, is not uncommon and has been reported. Cochlear circulatory dysfunction has been suggested to be linked to sudden sensory-neural hearing loss (SNHL) secondary to bacterial infections which produce lethal levels of cytokines that disrupt the inner ear [25]. Moreover, a case study which analysed eighteen cases of $\mathrm{C}$. canimorsus meningitis revealed that in nearly $50 \%$ of the cases, CSF analysis showed predominance of lymphocytes and commonly presented with acute or sub-acute hearing loss [26-28].

A study carried out in Finland during 2000-2017 Reference ???, isolated C. Canimorsus from 73 blood cultures from patients treated at the Helsinki University Hospital. Serotyping by PCR and Western Blot identified 3 serovars or variants (A, B and C) which were found to cause most of the infections in humans $(91.8 \%)$. The relative prevalence of these serovars was low amongst dog isolates $(7.6 \%)$ - indicating that these serovars are mostly virulent in humans. The low incidence of infection was due to the low prevalence of the virulent serovars in the oral cavities of dogs. This is despite the fact that C. Canimorsus itself is commonly found in up-to $67-86 \%$ of dogs (as previously stated). It further reiterates the fact that virulence of different serovars and not the actual prevalence of C. Canimorsus was what accounts for the rarity of this infection [29, 30].

As previously described, C. canimorsus grows very slowly and was difficult to identify via conventional methods of culture. Hence $16 \mathrm{~S}$ rDNA sequencing is now being increasingly useful in identification of such organisms. While quantitative PCR sequencing targets specific (most common) organisms, 16S rDNA PCR sequencing uses DNA from specimens and checks for a match against a gene bank. Most laboratories initially test samples for common disease-causing organisms. If the initial tests fail to identify the offending agent and the suspicion for an infection remains high, specimens are then tested with broad range 16S rDNA sequencing (Figure 3: Flowchart explaining the process). The commercial techniques lack primers to identify these rare types of organisms. The turn-around time for rDNA PCR sequencing is only about 3-19 hours (depending on the facilities available) vs. conventional cultures which usually take up to an average of 6 days [31]. Guidelines published by British Infection Association Year??? Also recommend testing via PCR for $16 \mathrm{~S}$ ribosomal DNA, if blood/CSF cultures or quantitative/pathogenspecific PCR fails to identify the agent [32]. 


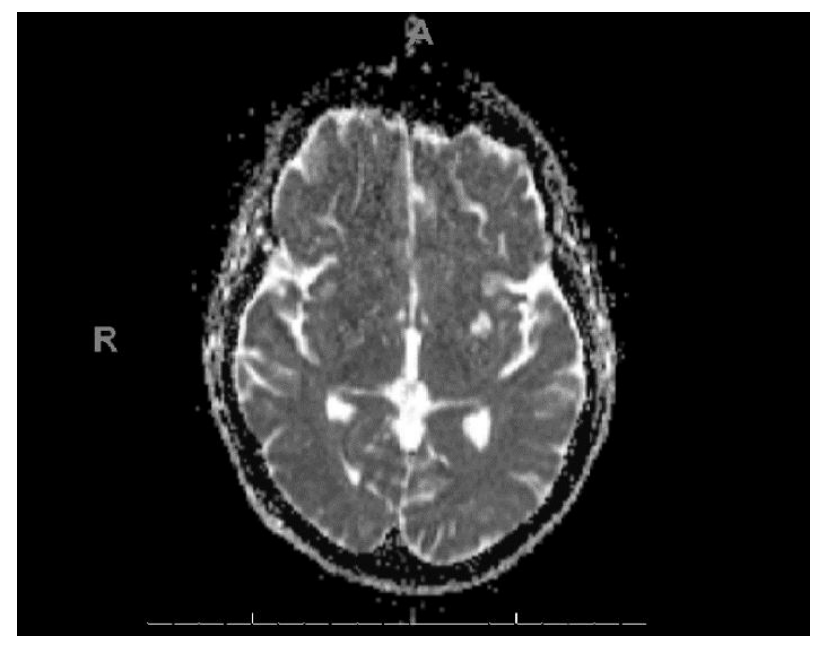

Similarly, another pilot study carried out by Jangsup Moon et al, year ??? revealed that the sequencing could be performed under 3 hours and successfully detected pathogenic bacteria from all samples under study . Their study concluded that this test should be increasingly employed in the future especially in cases like meningitis where disease fatality is high. $16 \mathrm{~S}$ Amplicon sequencing as it is alternatively known was found to be more sensitive. Moreover, the technique was found to be more sensitive and identified the causative agent even in antibiotic-treated samples. Undeniably, it was an indispensable tool in diagnostic medicine aiding timely identification and targeted treatment [33].

Meningitis is a serious and often fatal infection if not identified and treated early. Mortality rates of untreated cases approach 100 percent. Initial tests apart from CRP and Full blood count include blood cultures, CSF Analysis including biochemistry, gram staining, culture and PCR for specific organisms, most commonly meningococcal- and pneumococcal. According to guidelines published by National Institute of Health and Care Excellence (NICE) Year? Lumbar puncture for a CSF sample was the primary investigation. However, treatment should not be delayed whilst awaiting their results.

IV Ceftriaxone is the antibiotic of choice in suspected cases of bacterial meningitis above 3 months of age. Children younger than 3 months should receive IV Cefotaxime plus either Amoxicillin or Ampicillin. Length of antibiotic therapy varies between 7-14 days. Corticosteroids can be considered in cases where CSF was found to be frankly purulent [34].

\section{Conclusion}

\section{Learning Points and Take Home Messages}

1. High sensitivity and specificity of $16 \mathrm{~S}$ rDNA PCR in the identification of causative agent,

2. Correct identification of the causative agent aids in timely diagnosis and treatment, and

3. Prevention of antibiotic resistance when antibiotic treatment is directed towards a specific agent

\section{References}

1. Patel A, Harris KA, Fitzgerald F. (2017) What is broad-range 16S rDNA PCR? Archives of Disease in Childhood - Education and Practice 102:261-264.

2. Risum M, Ellekvist P. (2012) Capnocytophaga canimorsus meningitis diagnosed by means of a $16 \mathrm{~S}$ rRNA analysis. Ugeskr Laeg. 174(5):280-281.
3. Linton DM, Potgieter PD, Roditi D, Phillips A, Adams BK, Hayhurst M, et al. (1994) Fatal Capnocytophaga canimorsus (DF2) septicaemia. A case report. S Afr Med J. 84(12):857-860.

4. Van Dam AP, Jansz A. (2011) Capnocytophaga canimorsus infections in The Netherlands: a nationwide survey. Clin Microbiol Infect. 17(2):312-315.

5. Umeda K, Hatakeyama R, Abe $\mathrm{T}$, Takakura K, Wada $\mathrm{T}$, Ogasawara J, et al. (2014) Distribution of Capnocytophaga canimorsus in dogs and cats with genetic characterization of isolates. Vet Microbiol. 171(1-2):153-159.

6. Suzuki M, Kimura M, Imaoka K, Yamada A. (2010) Prevalence of Capnocytophaga canimorsus and Capnocytophaga cynodegmi in dogs and cats determined by using a newly established speciesspecific PCR. Vet Microbiol. 144(1-2):172-176.

7. Linton DM, Potgieter PD, Roditi D, Phillips A, Adams BK, Hayhurst M, et al. (1994) Fatal Capnocytophaga canimorsus (DF2) septicaemia. A case report. S Afr Med J. 84(12):857-860.

8. Bobo RA, Newton EJ. (1976) A previously undescribed gramnegative bacillus causing septicemia and meningitis. Am J Clin Pathol. 65(4):564-569.

9. Zangenah S, Abbasi N, Andersson AF, Bergman P. (2016) Whole genome sequencing identifies a novel species of the genus Capnocytophaga isolated from dog and cat bite wounds in humans. Sci Rep. 6:22919.

10. Hess E, Renzi F, Koudad D, Dol M, (2017) Cornelis GR. Identification of Virulent Capnocytophaga canimorsus Isolates by Capsular Typing. J Clin Microbiol. 55(6):1902-1914

11. Mally M, Shin H, Paroz C, Landmann R, Cornelis GR. (2008) Capnocytophaga canimorsus: a human pathogen feeding at the surface of epithelial cells and phagocytes. PLoS Pathog. 4(9):e1000164.

12. Shin H, Mally M, Kuhn M, Paroz C, Cornelis GR. (2007) Escape from immune surveillance by Capnocytophaga canimorsus. J Infect Dis. 195(3):375-386.

13. Manfredi P, Pagni M, Cornelis GR. (2011) complete genome sequence of the dog commensal and human pathogen Capnocytophaga canimorsus strain 5. J Bacteriol. 193(19):55585559.

14. Butler T. (2015) Capnocytophaga canimorsus: an emerging cause of sepsis, meningitis, and post-splenectomy infection after dog bites. Eur J Clin Microbiol Infect Dis. 34(7):1271-1280.

15. Mader N, Lührs F, Herget-Rosenthal S, Langenbeck M. (2019) Being Licked by a Dog Can Be Fatal: Capnocytophaga canimorsus Sepsis with Purpura Fulminans in an 
Immunocompetent Man. Eur J Case Rep Intern Med. 6(10):001268.

16. Sakai J, Imanaka K, Kodana M, Ohgane K, Sekine S, Yamamoto $\mathrm{K}$, et al. (2019) Infective endocarditis caused by Capnocytophagacanimorsus; a case report. BMC Infect Dis. 19(1):927.

17. Ahmad S, Yousaf A, Inayat F, Anjum S. (2019) Capnocytophaga canimorsus-associated sepsis presenting as acute abdomen: do we need to think outside the box. BMJ Case Rep.12(3):e228167.

18. Manfredi P, Lauber F, Renzi F, Hack K, Hess E, Cornelis GR. (2015) New iron acquisition system in Bacteroidetes. Infect Immun. 83(1):300-310.

19. Zangenah S, Andersson AF, Özenci V, Bergman P. (2017) Genomic analysis reveals the presence of a class D beta-lactamase with broad substrate specificity in animal bite associated Capnocytophaga species. Eur J Clin Microbiol Infect Dis. 6(4):657-662.

20. Domingues RB, Santos MVD, Leite FBVM, Senne C. FilmArray Meningitis/ Encephalitis (ME) panel in the diagnosis of bacterial meningitis. Braz J Infect Dis.

21. Butler T. (2015) Capnocytophaga canimorsus: an emerging cause of sepsis, meningitis, and post-splenectomy infection after dog bites. Eur J Clin Microbiol Infect Dis. 34(7):1271-1280.

22. de Boer MG, Lambregts PC, van Dam AP, van 't Wout JW. (2007) Meningitis caused by Capnocytophaga canimorsus: when to expect the unexpected. Clin Neurol Neurosurg. 109(5):393-398

23. Hansen M, Crum-Cianflone NF. (2019) Capnocytophaga canimorsus Meningitis: Diagnosis Using Polymerase Chain Reaction Testing and Systematic Review of the Literature. Infect Dis Ther. 8(1):119-136.

24. Wilson JP, Kafetz K, Fink D. (2016) Lick of death: Capnocytophaga canimorsus is an important cause of sepsis in the elderly. BMJ Case Rep.2016:bcr2016215450.
25. Tamura A, Matsunobu T, Kurita A, Shiotani A. (2012) Hemophagocytic syndrome in the course of sudden sensorineural hearing loss. ORL J Otorhinolaryngol Relat Spec. 74(4):211-214.

26. Gasch O, Fernández N, Armisen A, Verdaguer R, Fernández P. (2009) Community-acquired Capnocytophaga canimorsus meningitis in adults: report of one case with a subacute course and deafness, and literature review. Enferm Infecc MicrobiolClin. 27(1):33-36.

27. Cadre B, Al Oraimi M, Grinholtz-Haddad J, Benkhatar H. (2019) "My Dog Deafened Me!": Case Report of Capnocytophaga canimorsus Infection and Literature Review. Laryngoscope.129(1):41-43.

28. van Samkar A, Brouwer MC, Schultsz C, van der Ende A, van de Beek D. (2016) Capnocytophaga canimorsus Meningitis: Three Cases and a Review of the Literature. Zoonoses Public Health. 09;63(6):442-448.

29. Hess E, Renzi F, Karhunen P, Dol M, Lefèvre A, Antikainen J, et al. (2018) Capnocytophaga canimorsus Capsular Serovar and Disease Severity, Helsinki Hospital District, Finland, 2000-2017. Emerging Infect Dis. 12;24(12):2195-2201.

30. Renzi F, Hess E, Dol M, Koudad D, Carlier E, Ohlén M, et al. (2018) Capsular serovars of virulent Capnocytophaga canimorsus are shared by the closely related species C. canis and C. cynodegmi. Emerg Microbes Infect. 4;7(1):124.

31. Bialasiewicz S, Duarte TPS, Nguyen SH, Sukumaran V, Stewart A, Appleton S, et al. (2019) Rapid diagnosis of Capnocytophaga canimorsus septic shock in an immunocompetent individual using real-time Nanopore sequencing: a case report. BMC Infect Dis. 24;19(1):660.

32. Moon J, Kim N, Kim TJ, Jun JS, Lee HS, Shin HR, et al. (2019) Rapid diagnosis of bacterial meningitis by nanopore $16 \mathrm{~S}$ amplicon sequencing: A pilot study. Int J Med Microbiol. 309(6):151338. 